\title{
A relação entre a busca de informação e a escolha do canal de distribuição nas compras dos serviços de viagem de Pernambuco
}

The relation between information search and the distribution channel choice of travel services in Pernambuco

La relación entre la búsqueda de información y la elección del canal de distribución en la compra de viajes en Pernambuco

http://dx.doi.org/10.18472/cvt.18n1.2018.1374

Gabriela Cristina Pinheiro de Melo 〈gabrielacpmelo@gmail.com > Universidade Federal de Pernambuco (UFPE), Recife, PE, Brasil

Carla Borba da Mota Silveira <carlaborbasilveira@gmail.com > Universidade Federal de Pernambuco (UFPE), Recife, PE, Brasil

André Falcão Durão 〈afdurao@gmail.com >

Universidade Federal de Pernambuco (UFPE), Recife, PE, Brasil

**Artigo indicado como parte do processo fast-track do Semead 2016.

CRONOLOGIA DO PROCESSO EDITORIAL

Recebimento do artigo: 14-dez-2016

Aceite: 16-out-2017

FORMATO PARA CITAÇÃO DESTE ARTIGO

MELO, G. C. P. de; SILVEIRA, C. B. da M.; DURÃO, A. F. A relação entre a Busca de Informação e a escolha do Canal de Distribuição nas compras dos serviços de viagem de Pernambuco. Caderno Virtual de Turismo. Rio de Janeiro, v. 18, n.1, p. 205-222, abr. 2018.
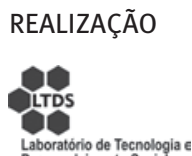
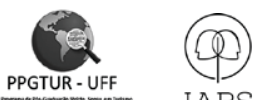

IABS

APOIO INSTITUCIONAL

COPPE

UFR]
EDIÇÃO

ERTORA
PATROCÍNIO

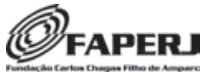




\section{RESUMO}

Os avanços tecnológicos redesenharam a cadeia de distribuição do turismo. O objetivo deste estudo é analisar a relação entre a busca de informação e a escolha do canal de distribuição na compra dos serviços de viagem do visitante de Pernambuco. Como base teórica, foi abordada a Tecnologia da Informação e Comunicação e seus impactos, comportamento de compra e distribuição dos serviços turísticos, segundo autores como Buhalis (2002), Brasil (2008) e Xiang et al. (2015). Em termos metodológicos, caracteriza-se como uma pesquisa exploratória descritiva, com abordagem quantitativa, utilizando o levantamento tipo survey, com amostra não probabilística por conveniência. Foram entrevistadas 168 pessoas, em abril e maio de 2016, visitantes do estado de Pernambuco. O resultado da análise indicou que há pouca relação, direta e condicional, entre a busca e a finalização da compra. Resultado checado, uma vez que a finalização de compra dos visitantes estudados sofreu variações para cada tipo de serviço turístico.

Palavras-chave: Tecnologia. Canais de Distribuição. Serviços Turísticos.

\section{ABSTRACT}

Technology has rebuilt Tourism supply chain. In this scenario, the present study aims to analyze the relationship between the search for information and the choice of distribution channel, in the Pernambuco visitors' purchases of travel services. As a theoretical basis for the study, the constructs Information and Communication Technology and its impacts, Buying behavior and Distribution of tourist services were exposed according to authors such as Buhalis (2002), Brasil (2008) and Xiang et al. (2015). In methodological terms, it is characterized as a descriptive exploratory research, with quantitative approach, and survey procedure type, with convenience non-probabilistic sample. 168 people were interviewed, in April and May 2016, visitors from the state of Pernambuco who participated in the process of buying travel services. The analysis results indicated that visitors purchase choices suffered variations for each kind of tourist services. This results were checked, once the visitors' choice of distribution channel suffered variations for each travel service.

Keywords: Technology. Distribution Channels. Tourist Services.

\section{RESUMEN}

La tecnología ha rediseñado la cadena de distribución del Turismo. El objetivo de este estudio es analizar la relación entre la búsqueda de información y la elección del canal de distribución en la compra de servicios del viaje del visitante Pernambuco. Como base teórica, fueron expuestos los constructos de Tecnología de la información y la comunicación y sus impactos, Comportamiento de compra y Distribución de los servicios turísticos según autores como Buhalis (2002), Brasil (2008) y Xiang et al. (2015). En términos metodológicos, se caracteriza como una investigación exploratoria descriptiva, con abordaje cuantitativo, utilizando como procedimiento el levantamiento tipo survey, con muestra no probabilística por conveniencia. Se entrevistaron 168 personas, en Abril e Mayo de 2016, entre visitantes del estado de Pernambuco que hayan participado en el proceso de compra de los servicios turísticos. El resultado del análisis indicó que existe poca relación, directa y condicional entre la búsqueda y la compra. Resultado comprobado, ya que la compra de visitantes estudiados sufría variaciones para cada tipo de servicio turístico.

Palavras clave: Tecnología. Canales de Distribución. Servicios Turísticos. 


\section{INTRODUÇÃO}

O avanço da Tecnologia da Informação e Comunicação (TIC) proporcionou um maior acesso às informações, antes de domínio exclusivo dos canais de distribuição, principalmente nas agências e operadoras de viagem. Esse livre acesso modificou não somente o comportamento do consumidor, muito mais consciente e ativo no processo de compra, mas também a dinâmica da cadeia de distribuição contemporânea. Segundo O'Connor e Frew (2000), a web permitiu que as organizações distribuíssem seus produtos não só de maneira direta, mas também através de uma ampla gama de canais, ou seja, além da oportunidade da venda direta, o desenvolvimento da TIC gerou novos canais, com processos de desintermediação e reintermediação. Esse cenário de abundância de informações e canais para finalização da compra deixou ainda mais complexo o sistema de consumo de bens e serviços.

Se para alguns negócios os avanços tecnológicos representam uma ameaça, para outros, como a prestação de serviço no turismo, é a oportunidade de criar novas empresas, com sistemas eficientes, personalização simultânea e custos reduzidos.

O turismo tem crescido acima da expectativa nos últimos anos, apresentando em 2014 um total mundial de 1,135 bilhão de turistas internacionais, segundo a Organização Mundial do Turismo (OMT, 2014). No mesmo ano, o Brasil recebeu mais de 6,4 milhões de turistas internacionais e em Pernambuco o número foi de cerca de 78 mil turistas estrangeiros (MTUR, 2014). Somam-se a estes os turistas domésticos, gerando mais de um milhão de reais circulados no estado graças ao turismo (GALENO, 2014). Todas essas movimentações e transações dos serviços turísticos são feitas em uma rede de multicanais, on-line e offline, em constante modificação para atender às demandas do turista.

O desenvolvimento das TICs trouxe uma nova dinâmica às relações comerciais. Percebe-se o uso cada vez maior das compras on-line nos serviços de viagem, chegando à marca de 57\% do total das reservas do setor e um montante de 148,3 milhões de reservas de viagem por ano (STATISTIC BRAIN, 2015). Além do mercado através do qual é finalizada a compra, se on-line ou off-line, a complexa teia multicanal ainda oferece a opção de finalização por meio de serviços diretos e intermediados. Nesse quesito, percebe-se um crescente processo de desintermediação causado principalmente pelo acesso direto do consumidor ao fornecedor, através da internet e demais meios de comunicação. Esse cenário indica uma mudança no perfil do turista, cada vez mais informado e protagonista no planejamento de suas viagens.

O presente estudo surge na tentativa de responder ao seguinte problema: "Como se dá, em um cenário de avanço tecnológico, a relação entre a busca de informação e a escolha do canal de distribuição na compra dos serviços de viagem do visitante de Pernambuco?". Para tal, foram relacionadas as fontes de informação, acessadas pelo turista que chegaram ao estado, bem como a escolha do canal para a compra dos serviços de viagem. Assim, são apresentados tais canais utilizados e verificado como ocorre o processo de finalização da compra dos serviços da viagem do visitante de Pernambuco. Processo este que pode ocorrer nos mercados on-line ou off-line, de maneira direta ou intermediada.

A seguir, apresenta-se a fundamentação teórica deste trabalho. 


\section{TECNOLOGIA DA INFORMAÇÃO E COMUNICAÇÃO E SEUS IMPACTOS NO TURISMO}

É indiscutível o fato de que as Tecnologias de Informação e Comunicação (TICs), mais predominantemente a Internet, revolucionaram a relação do ser humano com o mundo, com o outro e consigo mesmo. Há mais de 20 anos discutem-se os impactos desse fenômeno no comportamento das pessoas, visto que a sociedade é parte da economia pertencente a uma rede, dentro de um sistema nervoso eletrônico. Esse cenário em rede tem afetado todo o processo de criação, troca e distribuição de valor entre pessoas, empresas e consumidores (CASTELLS, 2016).

Outros autores trabalharam mais concepções e entendimentos sobre as transformações da tecnologia e Internet na sociedade como Barney (2004), com a sociedade em rede, Friedman (2005), com a ideia do mundo plano, e Machado e Almeida (2010), que argumentam que essa sociedade da informação vai além das vertentes tecnológicas e econômicas para abarcar uma dimensão política e geracional/cultural. Ou seja, tal revolução não somente afeta as esferas institucionais como facilitadora de processos, mas também modifica a maneira de pensar e agir da sociedade contemporânea.

O caminho para esse maior acesso à informação só foi possível graças às inovações tecnológicas recentes, e a Internet representa a principal delas. Esse uso da Internet tem crescido ao longo dos anos em taxas extraordinárias. Segundo pesquisa global recente desenvolvida pela We Are Social (2017), da população mundial de 7,4 bilhões de pessoas, cerca de 3,8 bilhões acessam a Internet, representando um crescimento médio anual de 10\%. Destes, 2,8 bilhões são usuários de redes sociais, com média de crescimento anual de $21 \%$. Esse cenário tem causado mudanças significativas, como, por exemplo, nas relações comerciais, uma vez que criou um novo mercado, o virtual, que ampliou a gama de fornecedores acessíveis ao cliente, passando do âmbito local para o nível mundial.

O comércio eletrônico, de forma geral, ano a ano, apresenta números cada vez mais robustos. Em 2015 , cerca de $68 \%$ dos consumidores americanos disseram fazer compras on-line pelo menos uma vez ao mês, número maior que os $62 \%$ encontrados no ano anterior (NANJI, 2015). No Brasil, 23,1 milhões de consumidores virtuais realizaram pelo menos uma compra no primeiro semestre de 2016, volume $31 \%$ maior que em 2015, fortalecido pela migração das vendas do varejo físico para o canal on-line (EBIT FECOMÉRCIO, 2016). 18,8\% dessas transações foram feitas por smartphones e $81,2 \%$ por computador/ notebook.

Um dos setores mais afetados pelo surgimento das tecnologias de informação e comunicação, mais especificamente a Internet, foi o do turismo. Segundo pesquisa organizada pela Fecomércio (2015), chamada "Comportamento dos usuários na Internet", 69,8\% dos usuários paulistas entrevistados planejam viagens pela web para destinos de lazer. Entre as pessoas que utilizam a Internet como fonte de informação, 57,2\% concluíram a compra virtualmente. Para Silva e Mendes Filho (2016), a área é uma relevante incorporadora de tecnologia, em diversos segmentos. Para os autores, o crescimento e fortalecimento do turismo têm uma forte dependência da capacidade de inovação e do uso da tecnologia da informação e comunicação no aperfeiçoamento da gestão, desenvolvimento de novos produtos, potencializar a comunicação e promoção de serviços e produtos turísticos, bem como personalizar e transformar as experiências de viagens. 
O crescimento exponencial das redes sociais (um dos principais "produtos" da evolução das TICs), por exemplo, mudou a dinâmica da comunicação on-line (SIGALA et al., 2012). As redes sociais estão se tornando, cada vez mais, um dos principais canais de distribuição e troca de informação, por exemplo, entre empresas turísticas e turistas. Em um cenário de intensa interação, proporcionada pela Web 2.0, encorajam os usuários a cocriar suas experiências, entre eles e com empresas. Redes sociais, como Facebook, Youtube, Twitter ou Instagram proporcionam às organizações de marketing digital e aos turistas um ambiente para interagir, comentar e partilhar suas experiências individuais e construir um ambiente comunitário (NEUHOFER et al., 2012). O uso quase que onipresente do smartphone por consumidores em toda fase do consumo é outro reflexo do surgimento e evolução das TICs.

O crescimento dos smartphones e seus aplicativos de viagens, por exemplo, como argumentam Wang et al. (2012), cria novos locais de busca de informação, assim como contempla as necessidades "on the go" dos turistas, tornando-se essencial para a tomada de decisões rápidas. Já estão claras as mudanças e consequências na forma de fazer negócio e, essencialmente, como o consumidor se comporta. Xiang et al. (2015) apresentam uma diferença entre o tradicional e o novo em relação à utilização da Internet por turistas. A abordagem tradicional é aquela que tem como finalidade o planejamento da viagem, em "canais tradicionais" na Internet como as On-line Travel Agencies - OTAs. Já o novo uso da Internet seria identificado nos usuários de demanda instantânea (nas redes sociais), prevalentes em alguns segmentos, claramente usuários/turistas da geração Y. A evolução dessas mudanças de comportamento dos consumidores dos serviços turísticos, em função do surgimento e desenvolvimento das TICs, será vista a seguir.

\section{COMPORTAMENTO DE COMPRA DO NOVO TURISTA}

De maneira particular, a natureza intangível dos serviços turísticos faz com que o comportamento desse consumidor seja naturalmente diferente daqueles que envolvem o processo decisório de bens de consumo, uma vez que estes apresentam muitos aspectos distintos a serem considerados (OCKE, 2013). Por essa necessidade de se considerar uma ampla gama de aspectos, a demanda do consumidor de serviços turísticos por informação é ainda mais intensa. Adicionada a essa realidade, a tecnologia da informação e comunicação impactou a área de forma definitiva.

A evolução desses impactos na forma como o consumidor turista se comporta e como acessam informação em todo o processo do usufruto do serviço são claros. Uma das fases mais importantes, a da busca por informação antes da viagem, foi especialmente afetada. Essa evolução começa com a quase total dependência da Internet pelo consumidor na busca de informação, considerando-a uma memória externa (SPARROW et al., 2011). Esse contexto é potencializado pelo grande crescimento das mídias sociais e como elas modificaram a dinâmica da comunicação virtual (SIGALA et al., 2012; GRETZEL, 2011), além do surgimento da tecnologia móvel, com smartphones e aplicativos de viagens, suprindo necessidades imediatas de informação, proporcionando aos consumidores um quase protagonismo total nas decisões no planejamento e durante as viagens (WANG et al. 2012).

Uma pesquisa robusta, realizada ao longo de seis anos, sobre os hábitos de planejamento de viagens na Internet foi feita por Fesenmaier e Xiang (2014) e Xiang et al. (2015). Os resultados desses estudos apontaram para realidades e tendências no uso da Internet por viajantes: (1) o uso da Internet para planejamento de viagem é plenamente adotado e saturado. A Internet e suas ferramentas, como os 
metabuscadores, são fonte número um para busca de informação. Informações e transações clássicas de uma viagem efetuadas por Internet, como a compra de uma passagem aérea, reserva em hotel e aluguel de carro, continuam dominando o mercado turístico on-line. Os metabuscadores aparecem como uma ótima ferramenta na análise das alternativas. A volatilidade nos preços criou uma grande ansiedade sobre quando realizar a reserva de produtos turísticos, e tais ferramentas, que suportam benchmarking de preços para os compradores, podem ajudar a amenizar essa ansiedade (GASDIA; RHEEM, 2012); (2) apesar de diferentes momentos na adoção da Internet na vida cotidiana, de forma geral, todas as gerações (principalmente os boomers, $\mathrm{X}$ e Y) têm a rede como a principal ferramenta para planejamento de suas viagens, mesmo destacando o uso e engajamentos maiores por parte da geração Y, que decide muita coisa sobre sua viagem em cima da hora ou já no destino; (3) e as diferenças de comportamento dessa geração têm como suporte as redes sociais, os dispositivos móveis e canais de informações emergentes. Isso, de fato, tem alterado o modus operandi de como consumidores agem no processo de decisão de compra, mesmo que o "canal" da informação mude, como é o caso das informações de terceiros.

Classicamente, dentro do estudo do marketing, no processo de busca de informação para tomada de decisão, as informações que têm maior grau de credibilidade são advindas de outras pessoas, as chamadas fontes de grupos, e de organizações independentes, as fontes públicas. Essas tendem a ser consideradas de alta confiabilidade e exercem maior influência na decisão de compra dos consumidores.

Em seu estudo sobre a preferência entre Sistemas de Entrega de Serviços (SESs) na compra de passagens aéreas, Brasil (2008) avaliou a influência de cinco fatores na decisão de compra dos consumidores: Link social - que é a preferência pelo contato humano na obtenção de serviços; Propensão ao uso de novas tecnologias - característica do indivíduo que prefere os autosserviços; Risco percebido - que é a consciência das consequências de alternativas e a possibilidade de ocorrerem; Controle percebido - ocorre na relação do ser humano com o ambiente, sendo a tentativa de demonstrar seu domínio; e a Conveniência, que está relacionada ao gasto de tempo e energia em alguma atividade.

Sobre os fatores que interferem nas escolhas do turista, Sirakaya e Woodside (2005) comparam o processo de seleção a um funil, com o qual viajantes limitam escolhas em meio a alternativas e são influenciados por fatores sociopsicológicos e não psicológicos. E muitos desses fatores afetam não só os produtos que os consumidores escolhem, mas qual processo eles usam para chegar a uma decisão.

Em uma realidade mais atual, os resultados das pesquisas citadas anteriormente, agora em um contexto on-line, podem ser corroborados com os achados de Fileri e Macley (2013). Os autores desenvolveram um estudo no qual analisavam fatores que influenciavam os turistas que planejavam sua viagem na adoção de informação de avaliações on-line de consumidores que já tinham vivenciado os serviços. Os on-line reviews são como se fossem o tradicional boca a boca. Os resultados indicaram que fatores, como classificação do serviço, a precisão da informação, a sua relevância, ocasião e pontualidade, são preditores fortes para a adoção dessas informações por turistas que estão planejando suas viagens. Esses dados são elementos relevantes que evidenciam como a distribuição dos serviços turísticos mudou ao longo dos anos, onde o consumidor passa a ter o protagonismo nas suas escolhas e no consumo de toda a cadeia produtiva do turismo. Essa nova realidade é exposta a seguir. 


\section{AS MUDANÇAS NA DISTRIBUIÇÃO DOS SERVIÇOS TURÍSTICOS}

Os canais de distribuição sofreram grandes mudanças nas últimas décadas. A década de 1960 teve como tecnologia principal o desenvolvimento dos Computer Reservations Systems (CRS) para que as agências e operadoras atendessem às demandas dos clientes dentro de uma lógica de distribuição do produto turístico onde estes exerciam uma clara função de intermediários. Em seguida, os Global Distribution Systems (GDS), na década de 1980 demonstravam o advento do que seria uma revolução tecnológica nos canais de distribuição com a chegada da Internet na década de 1990.

Essas mudanças de sistemas e a Internet no final dos anos 1990 transformaram drasticamente práticas operacionais e estratégicas no turismo (BUHALIS; LICATA, 2002; BUHALIS; LAW, 2007; BUHALIS; SOO, 2011). As companhias aéreas, pioneiras dessa comercialização informatizada no setor turístico, também foram as primeiras a utilizarem a Internet como ferramenta de acesso direto ao consumidor.

Desde 1993, a Internet iniciou processo contínuo de desintermediação e reintermediação da estrutura básica de distribuição do produto turístico, alterando totalmente o modelo tradicional no qual o mercado do agenciamento turístico funcionava. (SHELDON, 1997; WERTHNER; KLEIN, 1999 apud XIANG et al., 2015).

Durante a primeira parte da década de 1990, o setor de turismo adotou a Internet como o novo canal de distribuição dos seus produtos, o que permitiu conexões que quebraram barreiras de acesso de novos intermediários diretamente com o consumidor final, e permitiam que os sistemas ganhassem interfaces mais amigáveis e de fácil manuseio (WERTHNER; KLEIN, 1999 apud XIANG et al., 2015). Isso beneficiou tanto clientes quanto os distribuidores que faziam parte da cadeia distributiva. Essa década transformou o mercado de turismo líder no uso de plataformas que conseguiam se comunicar bem com o seu público final (XIANG et al., 2015).

Essa mudança provocou uma série de adaptações, principalmente na forma de comercializar os produtos e serviços turísticos nas agências de viagens e nas operadoras. $\mathrm{O}$ acesso direto dos clientes aos fornecedores através das plataformas on-line alterou o papel das agências de viagens. Nesse sentido, os clientes são empoderados a cada avanço tecnológico a buscar sua própria maneira de acessar os destinos, os produtos e serviços turísticos do seu interesse. Gretzel et al. (2006) argumentam que o avanço da Internet e a interação com as mídias sociais mudaram a forma de comunicar e se relacionar com o marketing no mercado de turismo. De fato, esse argumento reforça a necessidade clara de uma adaptação cada vez mais rápida aos elementos tecnológicos que auxiliam as vendas dos produtos turísticos on-line.

Ainda sobre a adaptação desses novos canais de distribuição, o período de 2001 até o presente, estabelece o consumidor como o principal player da distribuição turística, estando este cada vez mais empoderado em suas compras diretas, assim como nos reviews que produzem e que influenciam a compra de outros potenciais consumidores (XIANG et al., 2015).

Diante desse cenário dinâmico e repleto de variáveis, buscou-se entender o processo de compra dos serviços turísticos do visitante de Pernambuco, sendo realizada a pesquisa a seguir. 


\section{PROCEDIMENTOS METODOLÓGICOS}

O turismo, como fenômeno social multifacetado, é abordado pelas mais diferentes áreas de conhecimento e pode ser analisado por diversos métodos de pesquisa. Esta tem a abordagem quantitativa de natureza aplicada que, conforme Gil (2010), tem como principal foco identificar os fatores que determinam ou que contribuem para a ocorrência dos fenômenos. Quanto aos objetivos, caracteriza-se como uma pesquisa exploratória descritiva, pois busca maior aprofundamento no conhecimento do comportamento do consumidor/turista na busca de informação nos canais de distribuição (FLICK, 2012). Já como meio para sua realização, quanto aos procedimentos, foi feito um levantamento de campo ou survey, caracterizado pela interrogação direta das pessoas cujo comportamento se deseja conhecer (MALHOTRA, 2012).

Foi selecionado o questionário como ferramenta de coleta de dados, pois de maneira impessoal foi possível atingir um grande número de pessoas e garantir o anonimato dos respondentes (GIL, 2010). A coleta foi dividida em dois momentos: Pesquisa no Aeroporto Internacional de Recife/Guararapes: Gilberto Freyre (Questionário 1 - Q1) e a Pesquisa On-line (Questionário 2 - Q2). Considerando o contexto da pesquisa e as decisões tomadas pelos pesquisadores sobre tal contexto (explicado posteriormente), a amostra selecionada foi do tipo não probabilística por conveniência, com análise descritiva dos dados, uma vez que não se utilizou critérios estatísticos numericamente válidos, e sim, os deliberados pelos pesquisadores sendo vantajosos no tocante a custo e tempo despendidos (MALHOTRA, 2012).

O critério selecionado para a primeira etapa de coleta foi possibilitar uma amostragem por facilidade de acesso, sendo escolhido o Aeroporto Internacional dos Guararapes por ser o principal portão de entrada dos turistas no estado.

Para a segunda etapa, foi utilizado o Google Form, uma ferramenta gratuita de questionários e pesquisas on-line e possível de ser compartilhada via os mais diversos meios digitais existentes. Para que o questionário alcançasse o público-alvo, foram destacadas nas publicações as características condicionantes ao perfil desejado e adaptada a técnica metodológica Bola de Neve (GIL, 2010; FLICK, 2012) para as mídias sociais, com indicação de novos indivíduos pelos próprios respondentes do questionário. A pesquisa online ficou disponível durante todo o mês de maio de 2016 e, nesse período, o anúncio da pesquisa precisou ser publicado repetidas vezes para que estivesse sempre acessível aos usuários da rede.

Além dos critérios expostos para a seleção da amostra, ao final da primeira etapa de coleta de dados, foi possível perceber que, entre os visitantes entrevistados que vinham a Pernambuco por compromisso ou obrigação (Visitantes por Obrigação - VO), havia aqueles que tinham envolvimento direto com o processo de compra dos serviços de viagem (VO'), e os que não tinham esse envolvimento direto (VO"). Desses últimos, foi gerado um número restrito de informações para análise do comportamento de compra e, por isso, foram retirados da análise. Então, com a finalidade de complementar os dados coletados até o momento e ainda possibilitar uma abrangência maior de visitantes, foi feita a coleta on-line voltada exclusivamente para o visitante cuja motivação principal não era um compromisso ou obrigação, os Visitantes Espontâneos (VE). Em resumo, foram consideradas respostas válidas (RV) as seguintes: $\mathrm{RV}=$ Q1 (VE + VO') + Q2 (VE). Foram, portanto, entrevistados no total 224 visitantes, sendo considerados, pelos critérios estabelecidos e já explicados, 168 questionários válidos. A coleta de dados no aeroporto se deu de 01 a 30 de abril de 2016 e no mês seguinte, maio, as informações foram obtidas no ambiente online. 
O termo "visitante", utilizado no título e durante todo o trabalho, refere-se às pessoas não residentes de Pernambuco que vieram ao estado entre 2015 e 2016 (VE + VO), excetuando-se aqueles cuja motivação principal tenha sido uma obrigação e não tenham tido envolvimento direto no processo de compra dos serviços de viagem (VO”). Já aqueles que, apesar de viajarem por compromisso, estavam envolvidos no processo de compra foram considerados na análise (VO').

Para a construção do primeiro questionário, foram elencados os dados desejados e elaboradas questões claras a fim de evitar duplicidade de entendimento e dados imprecisos (FLICK, 2012). Antes disso, foi aplicado um pré-teste, que gerou a reformulação de alguns itens para melhor adequação aos objetivos. Já na construção do segundo questionário, aplicado on-line, as questões utilizadas na primeira pesquisa de campo foram modificadas para uma linguagem mais acessível, a fim de que se evitasse a dupla interpretação e facilitasse o entendimento de termos técnicos. Aqui, foi utilizado o Google Form, ferramenta gratuita de questionários e pesquisas on-line e possível de ser compartilhada via os mais diversos meios digitais existentes.

\section{ANÁLISE DOS RESULTADOS}

\section{PERFIL DA AMOSTRA}

Com relação aos dados gerais, o perfil dos visitantes entrevistados foi majoritariamente feminino com idades entre 26 e 35 anos em ambas as pesquisas realizadas. Quanto à idade, especificamente, se for somado o número de entrevistados entre 26 e 55 anos é gerada a parcela de $75 \%$ do total de turistas entrevistados $(\mathrm{Q} 1+\mathrm{Q} 2)$. Esse resultado é semelhante à pesquisa da Empresa de Turismo de Pernambuco (Empetur), no ano de 2015, cujos dados revelaram que 69,1\% dos visitantes do estado de Pernambuco têm idade entre 26 e 50 anos (PANROTAS, 2016).

Outro resultado obtido que também se assemelha com tais dados oficiais, é a região de origem da amostra entrevistada. Os dados oficiais destacam os estados da Região Sudeste entre os maiores emissores de turistas para Pernambuco: São Paulo (25\%), Rio de Janeiro (12,1\%) e Minas Gerais (8,4\%). Nos dados desta pesquisa também houve uma maior demanda turística da Região Sudeste do País (Q1 - 45,22\% e Q2 - 52,83\%), seguida pelo Nordeste (Q1 - 23,48\% e Q2 - 15,09\%). Essas duas regiões brasileiras, quando somadas, representam mais da metade dos visitantes entrevistados.

O caminho percorrido por cada turista no processo de compra está diretamente ligado à satisfação das necessidades que o motivou a viajar. Logo, essa questão não somente esteve presente nos questionários, como também foi critério para seleção de amostra, como detalhado anteriormente, quando abordada a metodologia adotada. Tudo isso levou à constituição de maior parcela dos visitantes entrevistados de turistas a lazer (Q1 - 64\% e Q2 - 55\%); seguidos por aqueles cuja motivação principal foi a de visitar parentes e amigos (Q1 - 17\% e Q2 - 45\%). O número de visitantes por alguma obrigação ou compromisso foi intencionalmente menor, como justificado anteriormente, e presente somente em Q1, constituindo ao final da coleta $12 \%$ de visitantes a negócios, eventos ou convenções e 1\% por motivo de saúde. 


\section{PROCESSO DE BUSCA DE INFORMAÇÃO}

Para a compreensão do processo da busca de informações e o conhecimento das fontes acessadas no planejamento da viagem dos visitantes de Pernambuco, foi solicitado que os entrevistados marcassem quantas das fontes presentes no questionário eles procuraram antes da compra dos serviços turísticos. Como resultado, pôde-se perceber que maioria dos entrevistados (Q1 - 66,1\% e Q2 - 52,8\%) citou como fonte de informação os metabuscadores (Figura 1), sites que fornecem dados, como preço, disponibilidade, descrição e avaliação dos demais consumidores, permitindo ainda uma comparação pelo critério da escolha do usuário. Essa é uma sinalização da influência tecnológica no processo de escolha do turista e ainda indica a busca pela economia de tempo, pois em uma única ferramenta é possível executar duas fases da compra: a busca por informação e a avaliação das alternativas. Esses dados corroboram os estudos de Gasdia e Rheem (2012), Fesenmaier e Xiang (2014) e Xiang et al. (2015).

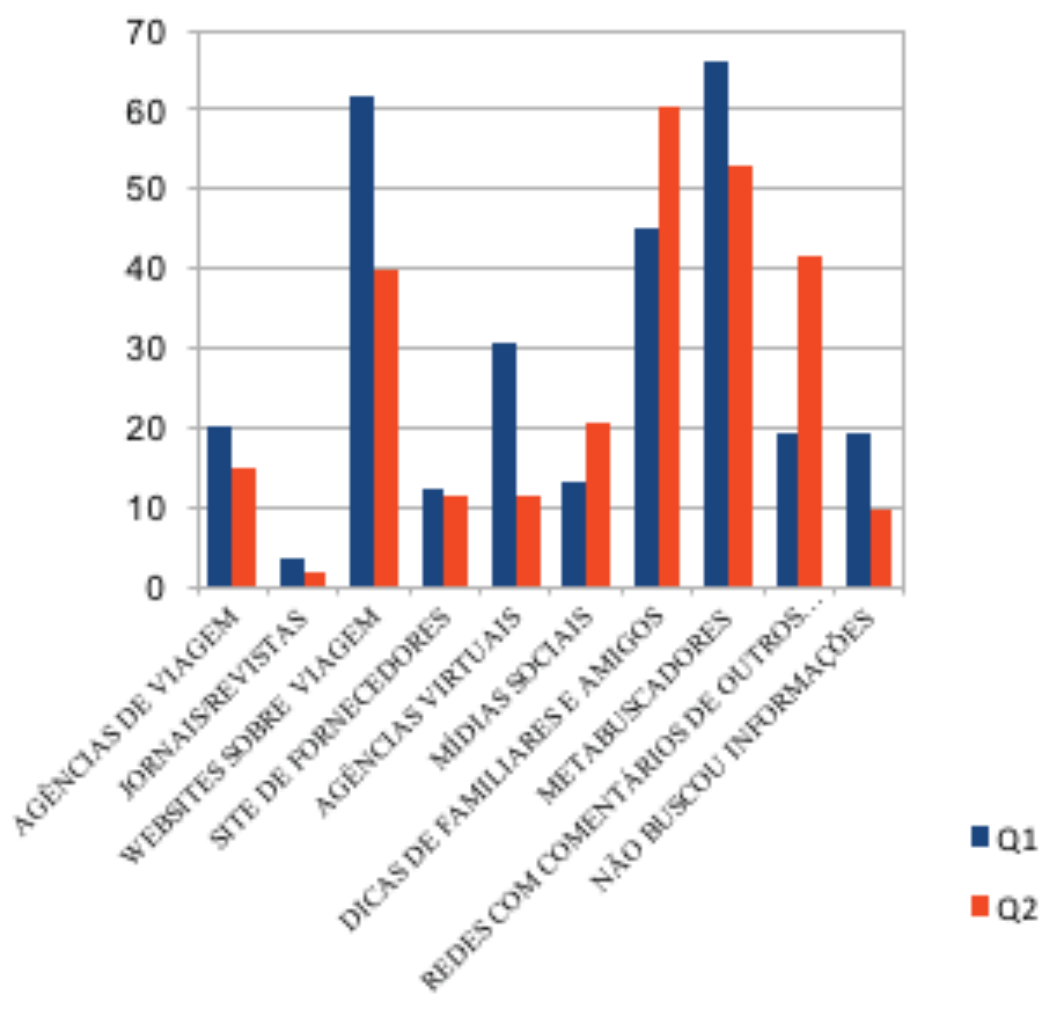

Figura 1 - Fontes de Informação acessadas pelos visitantes (\%)

Fonte: Autores, 2016.

Boa parte dos visitantes (Q1 - 45,2\% eQ2 - 60,4\%) também buscou informações de maneira interpessoal, com dicas de familiares e amigos. Tal resultado corrobora os achados dos estudos de Sirakaya e Woodside (2005) e Brasil (2008) que enquadram esse tipo informação com característica de alta confiabilidade e influência nas decisões de compra dos consumidores.

A presença da tecnologia no processo de compra do visitante de Pernambuco também é indicada pelo fato de seis fontes de informação, das nove citadas, serem pertencentes ao meio digital. Apesar de alternativas fechadas, vale salientar que era possível o acréscimo de outras fontes, diferentes das ali 
presentes. Como não foram citados novos meios para obtenção de informação por nenhum respondente, sugere-se que essas são as principais fontes acessadas durante a busca de informações dos visitantes de Pernambuco entrevistados.

Ao analisar os dados obtidos, é possível dividir as fontes de informação em fontes on-line e off-line. E, quando observadas dessa maneira, foi percebido que a maioria dos entrevistados com $43,48 \%$ em Q1 e 43,40\% em Q2 declarou ter acessado em ambos os ambientes, on-line e off-line; 13,04\% em Q1 e 24,5\% em Q2 somente no meio físico; 24,25\% em Q1 e 22,64\% em Q2 somente no virtual e 19,1\% em Q1 e 9,4\% em Q2 declararam não ter buscado informações sobre os serviços turísticos antes da compra. $\mathrm{O}$ destaque à ampla busca de informações, evidenciado pela maioria ter recorrido às fontes on-line e também às off-line, pode ser justificado pela compra de serviços de viagem ser considerada por muitos uma compra complexa, demandando uma decisão extensiva, aquela que envolve a consulta de grande variedade de fontes de informação, a comparação de diversas alternativas avaliadas de acordo com muitas características, e requer um investimento significativo de tempo e esforço.

\section{FINALIZAÇÃO DA COMPRA}

O produto turístico é composto por diferentes serviços que são fornecidos por uma infinidade de organizações. A fim de melhor visualizar os dados obtidos na busca pelos objetivos do presente trabalho, os serviços estudados foram reunidos nas seguintes categorias: passagens aéreas, meios de hospedagem e passeios turísticos ou atrações. Os demais serviços (transfer, seguro-viagem, etc.) foram agrupados na alternativa "outros serviços turísticos".

Com base na teoria estudada, foi possível a detecção de duas decisões principais na escolha de finalização da compra: quanto ao mercado e quanto à intermediação. Quanto ao mercado, o consumidor pode optar pelo mercado on-line - o qual representa o ambiente virtual de trocas entre oferta e demanda turística possibilitada pela Internet - ou pelo mercado off-line - espaço físico onde ocorre a troca entre a oferta e demanda turística por meio do contato interpessoal. Neste último, estão incluídas tanto as reservas e vendas realizadas pessoalmente nos balcões das lojas físicas quanto as realizadas remotamente via telefone.

Além da escolha do mercado, o visitante possui duas alternativas para finalizar sua compra: se de maneira direta - adquirindo o serviço diretamente com os fornecedores, ou intermediada - utilizando empresas intermediárias para alcançar os serviços dos fornecedores. Neste trabalho, foram consideradas empresas intermediárias qualquer empresa acessada para compra de um produto ou serviço que não fosse a produtora do mesmo.

Com os dados obtidos não foi possível traçar um padrão de compra comum aos quatro grupos analisados: passagens aéreas, meios de hospedagem, passeios/atrativos e demais serviços turísticos. Logo, foi avaliado o comportamento de cada conjunto de serviços, separadamente, possibilitando a consideração das especificidades e variáveis de cada um. 


\section{Passagens Aéreas e Meios de Hospedagem}

Foi possível notar a predominância de compras das passagens aéreas no mercado on-line (Q1 - 70,44\% e Q2 - 83,02\%), sendo 46,96\% em Q1 e 79,25\% feitas diretamente no site das companhias aéreas e 23,48\% em Q1 e 3,77\% em Q2 de maneira intermediada, corroborando a grande pesquisa feita por Fesenmaier e Xiang (2014) e Xiang et al. (2015). No caso das passagens aéreas, a grande familiaridade dos consumidores com os canais eletrônicos de compra direta pode ser justificada pelo pioneirismo do setor na informatização das reservas e inserção no $e$-commerce.

Se isolarmos os dados com base na intermediação, há uma discrepância entre o resultado da pesquisa realizada no aeroporto (Q1) e a pesquisa feita on-line (Q2). Na pesquisa Q1, 50,44\% dos entrevistados (2,61\% via telefone, $23,48 \%$ via Internet e $24,35 \%$ pessoalmente) compraram suas passagens de maneira intermediada (Agências de Viagem e Agências Virtuais). Já na pesquisa Q2, apenas 5,66\% (3,77\% via Internet e $1,89 \%$ pessoalmente) assim o fizeram.

O baixo percentual da intermediação de passagens aéreas da pesquisa realizada nos meios digitais (Q2) sugere um turista mais independente na compra de serviços de viagem e familiarizado com o meio virtual. Percebe-se na venda de passagens aéreas baixas ou, em alguns casos ausência de comissões. Assim, na tentativa de aumentar o lucro, muitos intermediários aplicam taxas administrativas que somadas ao valor da passagem, tornam o preço de venda desses canais mais elevados do que o preço de venda dos fornecedores. Fato percebido mais claramente ao se utilizar a Internet como rápida ferramenta de comparação. Além disso, os esforços promocionais das companhias - com programas de milhagem e facilidades de pagamento - contribuem para uma maior atratividade na venda direta.

Comportamento similar à compra de passagem aérea foi percebido na compra da hospedagem. Na pesquisa Q1, 60\% dos entrevistados utilizaram-se de alguma intermediação, enquanto na Q2 foram apenas $13,20 \%$.

Quanto ao mercado, os dados obtidos a respeito da compra dos meios de hospedagem também indicam uma preferência pelo mercado virtual. Um total de 43,47\% em Q1 e 58,49\% em Q2 dos visitantes entrevistados preferiu o mercado on-line, enquanto 29,8\% optaram pelas reservas off-line. Após a adoção tecnológica das companhias aéreas em seus processos, a hotelaria também passou a se inserir nas reservas informatizadas e vendas on-line. Sendo então, também na hospedagem, o tempo de presença na web um fator contribuinte para a alta adesão pelo mercado on-line na compra dos meios de hospedagem.

Outro fato que contribui para a grande adesão ao mercado on-line é que tanto as passagens aéreas quanto os meios de hospedagens contam com metabuscadores que auxiliam na busca e avaliação das alternativas pelo visitante. Durante a aplicação dos questionários presenciais, foi possível observar a citação recorrente de três metabuscadores para a compra desses serviços: o Decolar.com, Trivago e Booking.com. A diferença percebida pelos pesquisadores, durante as entrevistas, foi que na busca de passagens aéreas, grande parte dos entrevistados afirmou utilizar tais ferramentas para comparação, mas efetuavam a finalização diretamente no site da empresa escolhida, enquanto nas reservas de hotéis, os entrevistados informaram que pesquisavam e já reservavam no próprio metabuscador, que acaba passando de infomediário para um intermediador eletrônico de fato. 


\section{Passeios e Atrações Turísticas}

Nos serviços de passeios e atrações turísticas, foi grande o número de visitantes que acessaram os atrativos por meio de guias e condutores locais, um total de 45,22\% em Q1 e 33,96\% dos visitantes entrevistados em Q2. Com relação ao mercado, onde a compra desses serviços foi realizada, foi possível uma predominância de transações off-line, sendo apenas 2,62\% em Q1 compradas pela Internet e nenhuma em Q2.

Neste trabalho, são considerados fornecedores aquelas empresas que realizam os passeios e visitas aos atrativos, logo, estão enquadrados nessa categoria os guias de turismo, condutores e agências de receptivo. A partir daí, entende-se que a intermediação é feita pelas agências emissivas e pelos meios de hospedagem, ao indicarem parceiros responsáveis pelos passeios turísticos nos destinos. Nesse caso, percebeu-se pelos dados obtidos, uma baixa intermediação na compra de tais serviços, sendo a opção de apenas 10,43\% em Q1 e 7,5\% dos entrevistados em Q2.

É importante destacar também que nos questionários foram investigados como "passeios e atrações turísticas" as atividades pagas, nas quais são utilizados serviços turísticos geradores de custo para o visitante, tais como guias, uso de transporte turístico (lanchas e quadriciclos, por exemplo), entrada de museus, etc. Como os principais atrativos do estado de Pernambuco são as belezas naturais (MTUR, 2016), muitos visitantes consideraram que em sua viagem não tiveram gastos com passeios e atrações (Q1 - 41,74\% e Q2 - 30,19\%). Além disso, 17\% dos respondentes em Q1 e 45\% em Q2 tiveram como motivação principal a visita a amigos e parentes, logo, é provável que eles tenham apoio logístico para acesso aos atrativos turísticos e não dependam muito de serviços turísticos pagos.

Com uma simples pesquisa na Internet, é possível encontrar diversas opções de compra on-line dos passeios turísticos, principalmente por meio das agências de receptivo utilizando e-commerce. No entanto, apesar dessa conveniência, o presente trabalho indica uma preferência pela compra direta no mercado offline. Como visto, Brasil (2008) afirma que frente à percepção de maiores riscos associados ao uso de um determinado SES, o consumidor está disposto a aceitar menores níveis de conveniência no atendimento, abrindo mão parcialmente de itens como rapidez e economia de tempo ou de dinheiro, por exemplo. $\mathrm{Ou}$ seja, na percepção de maiores riscos associados ao uso de uma compra on-line com uma empresa pouco conhecida, o consumidor está disposto a aceitar menores níveis de conveniência no atendimento, optando por deixar a compra para o local de destino onde pode avaliar melhor os prestadores e as condições do serviço pessoalmente.

Mesmo com toda a evolução e dependência da Internet para busca de informação e planejamento de viagens, evidenciadas nas pesquisas de Sparrow et al. (2011), Gretzel (2011), Sigala et al. (2012) e Wang et al. (2012), dependendo da percepção de risco e de falta de informação sobre serviços, o consumidor pode escolher ainda processos off-line para decidir sobre sua compra ou não.

\section{Outros Serviços Turísticos}

A característica de destaque na análise da compra de outros serviços turísticos é o grande número de turistas que não utilizaram transfer, seguro ou outro produto de viagem (Q1 - 85,2\% e Q2 - 83\%). Talvez isso possa ser explicado pelo perfil dos respondentes, grande parte pertencente à geração $\mathrm{Y}$, que possui o comportamento mais alinhado com consequências proporcionadas pela tecnologia nos serviços turísticos, conforme as pesquisas de Fesenmaier e Xiang (2014) e Xiang et al. (2015). Entre os visitantes que utilizaram serviços turísticos secundários, a compra foi majoritariamente intermediada 
em ambas as pesquisas (Q1 - 6,5\% e Q2 - 7,5\%), seja através das agências de viagem ou através do site da companhia aérea, junto com a compra da passagem aérea. Os intermediários tendem a agregar serviços adicionais àqueles essenciais do turismo, como maneira de aumentar o valor percebido do produto e, consequentemente, melhorar as vendas.

\section{CONSIDERAÇÕES FINAIS}

A investigação teórica nos avanços tecnológicos do turismo aponta para uma transformação constante na cadeia distributiva do setor. Graças à Internet, ganharam espaço elementos provedores de informação, os infomediários, representados pelos metabuscadores e sites sobre viagem e turismo. Nesse contexto, vale destacar a influência daqueles cujas informações são produzidas pelo próprio turista, como as redes sociais e de comentários e avaliações sobre os serviços de viagem, muito utilizadas pela rápida atualização, alta confiabilidade do conteúdo, além, mais recente, dos aplicativos para equipamentos mobile, do tipo smartphones.

Recentemente, percebe-se ainda a mudança dos infomediários ao inserirem em suas páginas ferramentas de venda, tornando-se também intermediários na cadeia de distribuição do turismo. Ao mediar as transações do consumidor com o fornecedor, recebem uma comissão ou taxa de serviço pelas vendas. A grande adesão desses mecanismos pode ser explicada pelo fato de suas informações passarem confiabilidade ao consumidor, e também pela junção da etapa de busca com a de comparação das alternativas em um único ambiente. A finalização da compra por meio desses sites gera a sensação de realização de um bom negócio, uma vez que pesquisou e analisou a melhor opção de acordo com suas necessidades e fechou o serviço, tudo em um só lugar. É a disponibilidade da ferramenta capaz de entregar o produto certo, na hora certa, às pessoas certas.

No comportamento do consumidor, a literatura sobre o assunto evidencia cada vez mais a familiaridade com o mercado on-line e o uso da Internet para busca de informação no processo de planejamento de uma viagem, apesar de existirem nuances e particularidades em relação às gerações e adoção da Internet no seu dia a dia (WANG et al., 2012; FESENMAIER; XIANG, 2014; XIANG et al. 2015). Nos turistas isso é muito evidente, uma vez que o caminho percorrido por cada tipo de turista mostra-se diferente: turistas mais velhos, aqueles sem acesso à Internet, viajantes exploradores, turista de negócios, etc. Para o turista habitual, a compra deixa de ser tão complexa, permitindo a abreviação do processo de compra, podendo fazer com que as fontes internas sejam as únicas acessadas para avaliação das alternativas.

Quanto à busca de informação dos serviços de viagem, a maior parcela dos respondentes utilizou fontes de ambos os universos, o on-line e o off-line. Como mencionado na análise dos dados, isso mostra o envolvimento do visitante com um processo de compra complexo, demandando a consulta de grande variedade de fontes de informação. Nesse processo, a etapa de avaliação das alternativas também é criteriosa. Assim, para corroborar essa ideia, foi vista a grande utilização de metabuscadores, ferramentas comparativas que facilitam o processo de compra, diminuindo o investimento de tempo e esforço por parte do consumidor, conforme estudo de Gasdia e Rheem (2012).

Além disso, outro indicativo de alto envolvimento com a compra turística foi a grande consulta a familiares e amigos, demonstrando a busca por fontes confiáveis e seguras no suporte de sua decisão. Atualmente, essa busca também ocorre por meio de on-line reviews que recebem cada vez mais atenção dos 
pesquisadores, no sentido de compreender como essas informações escritas em plataformas conhecidas como e-word of mouth (WOM) impactam a tomada de decisão de consumidores (FILIERI; MCLEAY, 2013).

$\mathrm{Na}$ finalização da compra, verificou-se que os serviços considerados essenciais (passagem aérea e hospedagem) foram obtidos, em sua maioria, no mercado on-line. Precursoras na utilização de reservas informatizadas e vendas on-line, as companhias aéreas e empresas hoteleiras já possuem interfaces com transações cujos visitantes já estão familiarizados. Percebe-se também que a necessidade de reserva dos serviços essenciais, para a garantia das condições mínimas de viagem, aliada aos metabuscadores, ferramenta facilitadora na tomada de decisão, influenciam o consumidor na escolha pelo mercado on-line, ou seja, o visitante precisa desses serviços, tem uma ferramenta de comparação de alternativas facilitada pela Internet e ainda tem a possibilidade de finalizar a compra no mesmo ambiente. Conclui-se que, pela conveniência e confiabilidade nas empresas, o consumidor acaba finalizando sua compra por esses serviços no próprio mercado on-line.

Quanto à intermediação, a obtenção dos serviços essenciais diferiu nas pesquisas realizadas. Os resultados demonstram que pouco mais da metade dos entrevistados em Q1 utilizou serviçosintermediados, enquanto a maioria dos entrevistados em Q2 obteve serviços diretamente. Tais indicadores parecem apontar para a diferença no perfil dos pesquisados nesses dois contextos: na coleta realizada on-line (Q2), por um lado, acessou-se de forma mais uniforme um público formado por viajantes mais independentes no planejamento da viagem e na compra dos serviços turísticos, cuja identidade é caracterizada, de um modo geral e entre outras coisas, exatamente pelo uso de tecnologias, como as das plataformas usadas para responder à pesquisa; por outro lado, na coleta realizada pessoalmente no aeroporto $(\mathrm{Q} 1)$, onde o público é mais misto, utilizaram-se mais pacotes com serviços intermediados por alguma agência física ou virtual, porém, com uma diferença bem menor entre os valores que se referem à quantidade de escolhas finais diretas e indiretas.

Os passeios, atrativos turísticos e demais serviços foram obtidos predominantemente no mercado offline. $\mathrm{O}$ fato de serem serviços considerados secundários sob a óptica dos entrevistados pode fazer com que não haja urgência na compra de algum produto. Além disso, o risco percebido pela falta de informações, principalmente no tocante aos passeios, pode fazer os visitantes abrirem mão da conveniência de se comprar previamente, pela Internet, deixando a compra para quando estiverem nos destinos. No entanto, isso parece ser um empecilho cultural, uma vez que foi percebido na busca nas ferramentas turísticas da web um cenário diferente em destinos desenvolvidos como a Europa e os Estados Unidos. Nesses locais, há intenso uso de aplicativos como, por exemplo, get your guide e rent a local friend, que permitem o acesso previamente agendado a passeios e tours. Nota-se, inclusive, o uso predominante desses aplicativos em serviços e atrativos concorridos, para a garantia do acesso, além de agregar valor no sentido de evitar filas, por exemplo.

$\mathrm{Na}$ escolha do canal de distribuição dos passeios e atrações turísticas, especificamente, os visitantes preferiram os meios de acesso direto ao fornecedor. Enquanto isso, os demais serviços turísticos apresentaram maiores índices de intermediação. Apesar de serem considerados dispensáveis por muitos, os demais serviços turísticos têm sua importância no sistema turístico. Eles completam os serviços essenciais do turismo, e agregam valor ao pacote de viagem. Além disso, possuem comissões mais atrativas que os demais serviços, como é o caso de transfers, tours ou seguros-viagem. 
Assim, deve-se concluir que, quanto ao objetivo geral deste trabalho, não foi percebida uma forte relação, direta e condicional, entre a busca de informação e a escolha do canal de distribuição dos serviços turísticos de Pernambuco, ou seja, não é possível afirmar que aqueles que buscam mais informações online geralmente finalizam suas compras on-line, ou o contrário. Essa pouca relação, direta e condicional, pôde ser checada por meio dos dados obtidos, uma vez que a finalização de compra do visitante estudado sofreu variações para cada tipo de serviço turístico. Percebeu-se também que essas variações estão mais ligadas aos fatores intervenientes no processo de compra do que à etapa de busca de informações.

Como a pesquisa aplicada neste estudo teve características não probabilísticas, deve ter seus resultados encarados como estudo contribuinte, apresentando dados de uma parcela dos visitantes do estado de Pernambuco. Além disso, o presente trabalho foi baseado no cenário turístico atual da região, demandando facilmente em poucos anos a atualização dos dados para o novo cenário que se apresentará. Essa questão é ainda mais imperativa quando se envolvem os avanços tecnológicos e o comportamento humano, elementos em constante modificação e altamente sensíveis às transformações econômicas, sociais e culturais.

\section{REFERÊNCIAS}

BARNEY, D. The Network Society. Polity Press, Cambridge, 2004.

BRASIL. Ministério do Turismo. Portal oficial do Ministério do Turismo. Disponível em: 〈http://www. dadosefatos.turismo.gov.br> Acesso em: 25 out. 2016.

BRASIL, V. S. Canais de Distribuição no Turismo: uma análise das variáveis determinantes do uso de canais interpessoais e da Internet na compra de passagens aéreas. Turismo em Análise, v. 19, p. 45$63,2008$.

BUHALIS, D.; LAW, R. Progress in information technology and tourism management: 20 years on and 10 years after the Internet - The state of eTourism research. Tourism Management, v. 29, p. 609-618, 2007.

BUHALIS, D.; LICATA, M. C. The future eTourism intermediaries. Tourism management, v. 23, p. 207$220,2002$.

BUHALIS, D.; SOO, H. J. E-Commerce. Contemporary Tourism Reviews, p. 5-29, 2011.

CASTELLS, M. A sociedade em rede. São Paulo: Paz e Terra, 2016.

EBIT/FECOMÉRCIO. Webshoppers. 34. ed. 2016. Disponível em: 〈http://www.fecomercio.com.br/ public/upload/editor/pdfs/ws34_pt.pdf>. Acesso em: 06 jun. 2017.

FECOMÉRCIO. Comportamento dos usuários da Internet. 2015. Disponível em: 〈http://www. fecomercio.com.br/upload/file/2016/04/11/comportamento_usu_riosinternet.pdf $\rangle$. Acesso em: 06 jun. 2017.

FESENMAIER, D. R.; XIANG, Z. Tourism Marketing from 1990 to 2010: two decades and a new paradigm. In: McCabe, S. (Ed.). The Routledge Handbook of Tourism Marketing. Routledge, London, 2014.

FILERI, R.; MCLEAY, F. E-WOM and accomodation: an analysis of the factors that influence travelers adoption of information from on-line reviews. Journal of Travel Research. SAGE. p. 44-47. 2013. 
FLICK, U. Introdução à Metodologia de Pesquisa: um guia para iniciantes. Porto Alegre: Penso, 2012. FRIEDMAN, T. The World is Flat: a brief history of the twenty first century. Farrar, Straus \& Giroux: New York, 2005.

GALENO, B. Receita turística de Pernambuco ultrapassa R\$ 1 bilhão. PANROTAS, 2014. Disponível em: $\quad\langle$ http://www.panrotas.com.br/noticia-turismo/destinos/receita-turistica-de-pernambucoultrapassa-r\$-1-bilhao_97819.html>. Acesso em: 26 out. 2015.

GASDIA, M.; RHEEM, C. Mobile hits the mainstream: leisure and business traveler trends. PhoCusWright, 2012.

GIL, A. C. Como elaborar Projetos de Pesquisa. 5. ed. São Paulo: Atlas, 2010.

GRETZEL, U. Intelligent systems in tourism: a social science perspective. Annals of Tourism Research, V. 38, n. 3, p. 757-779, 2011.

GRETZEL, U.; FESENMAIER, D. R.; O'LEAREY, J. T. The Transformation of Consumer Behavior. In: BUHALIS, D., COSTA, C. (Ed.). Tourism Business Frontiers: consumers, products \& industry. Elsevier, Burlington, MA, 2006.

INFRAERO. Anuário Estatístico Operacional 2015. Página institucional da Infraero. Disponível em: 〈http://www.infraero.gov.br〉. Acesso em: 05 jun. 2016.

MACHADO, L. P.; ALMEIDA, A. Inovações e Novas Tecnologias. Porto: Princípia Editora, 2010.

MALHOTRA, N. Pesquisa de Marketing - uma orientação aplicada. 6. ed. Porto Alegre: Bookman, 2012.

NEUHOFER, B.; BUHALIS, D.; LADKIN, A. Conceptualising technology enhanced destination experiences. Journal of Destination Marketing \& Management, p. 36-46, 2012.

O'CONNOR, P.; FREW, A. Evaluating eletronic channels of distribution in the hotel sector: a delfi study. Information Technology and Tourism, v. 3, p. 177-193, 2000.

OCKE, M. A. O Processo de Decisão de Compra de Viagem de Férias da Família. Turismo em Análise, v. 24, n. 3, p. 503-520, dez., 2013.

ORGANIZAÇÃO MUNDIAL DO TURISMO (OMT). Annual Report 2014. UNWTO, Madrid, 2015. Disponível em: 〈http://www2.unwto.org/annualreport2014〉. Acesso em: 25 out. 2015.

PERNAMBUCO. Pernambuco é destaque em pesquisa do Ministério do Turismo. Página institucional do governo de Pernambuco. Disponível em: 〈http://www.pe.gov.br/ mobile/blog/2016/04/25/ pernambuco-e-destaque-em-pesquisa-do-ministerio-do-turismo〉. Acesso em: 05 jun. 2016.

SIGALA, M.; CHRISTOU, E.; GRETZEl, U. Social Media in Travel, Tourism, and Hospitality: theory, practice and cases. Sage: Oaks, CA, 2012.

SILVA, J. C.; MENDES FILHO, L. A. A influência das tecnologias de informação e comunicação nos destinos turísticos inteligentes. XXI Seminário de Pesquisa do CCSA UFRN, 2016.

SIRAKAYA, E.; WOODSIDE, A. G. Building and testing theories of decision making by travellers. Tourism Management, v. 26, p. 815-832, 2005.

SPARROW, B.; LIU, J.; WEGNER, D. M. Google effects on memory: cognitive consequences of having information at our fingertips. Science, v. 333, n. 6043, p. 776-788, 2011. 
STATISTIC Brain. Internet Travel Hotel Booking Statistics. Disponível em: «http://www.statisticbrain. com>. Acesso em: 25 out. 2015.

WANG, D.; PARK, S.; FESENMAIER, D. R. The role of smartphones in mediating the tourist experience. Journal of Travel Research, p. 51, n. 4, p. 371-387, 2012.

WE ARE SOCIAL. Digital in 2017: global review. Special Report, 2017. Disponível em: 〈https:// wearesocial.com/special-reports/digital-in-2017-global-overview〉. Acesso em: 06 jun. 2017.

XIANG, Z.; MAGNINI, V.; FESENMAIER, D. R. Information Technology and Consumer Behavior in Travel and Tourism: insights from travel planning using the internet. Journal of Retailing and Consumer Services, n. 22, p. 244-249, 2015.

XIANG, Z. et al. Adapting to the Internet: trends in travelers use of the web for trip planning. Journal of Travel Research, v. 54, n. 4, p. 511-527, 2015. 